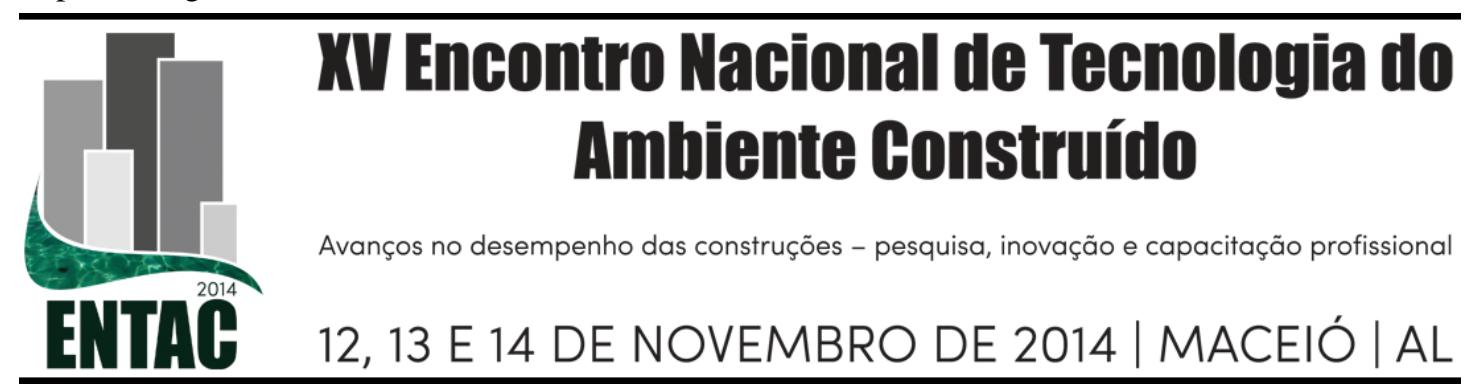

\title{
LEVANTAMENTOS DE ERROS EXECUTIVOS EM EDIFÍCIOS EM ALVENARIA ESTRUTURAL DE BLOCO CERÂMICO
}

\author{
SOUSA, Michel Wendell Silva (1); CABRAL, Antonio Eduardo Bezerra (2) \\ (1) GPMATE/UFC (2) GPMATE/PEC/UFC, eduardo.cabral@ufc.br
}

\begin{abstract}
RESUMO
A alvenaria estrutural está sendo um sistema construtivo bastante empregado no Brasil, principalmente com o incentivo que o governo está oferecendo com campanhas de habitação popular. Porém, apesar de ser um sistema construtivo bastante antigo, nota-se certa dificuldade dos profissionais que executam esse tipo de estrutura, que se evidenciam pela presença de várias falhas construtivas que se observam na obra durante a fase de elevação da alvenaria. Este trabalho tem como objetivo apontar os principais erros normalmente encontrados na fase de execução da alvenaria estrutural a partir de um levantamento de campo, comparando com os critérios de aceitabilidade descritos pela literatura nacional. Foi realizado um levantamento de campo numa empresa que atua em Fortaleza/CE executando prédios residenciais em alvenaria estrutural, onde, de posse desses dados, foi feita uma análise geral de quais erros executivos são mais incidentes na etapa de elevação das alvenarias, discutindo-se também as possíveis causas de tais ocorrências. Como resultado observou-se que os erros mais ocorrentes foram os desaprumos na alvenaria, erros de paginação com a utilização de blocos quebrados, o não preenchimento de diversas juntas com a argamassa e a falta de padronização quanto às espessuras dessas juntas. Uma medida importante que pode ser tomada para amenizar a maioria desses erros é a utilização de ferramentas adequadas e padronizadas e o emprego de mão-de-obra qualificada e preparada para esse tipo específico de sistema construtivo.
\end{abstract}

Palavras-chave: alvenaria estrutural, erros executivos, manifestações patológicas.

\begin{abstract}
The structural masonry is constructive system very used in Brazil, especially with the incentive that the government is offering due to public housing campaigns. However, despite being a fairly old building system, there is some difficulty who perform this type of structure, which are evidenced by the presence of several construction flaws that are observed in the work during the elevation of the masonry. This paper aims to describe the main errors usually found in the implementation phase of structural masonry from a field survey, compared with the acceptability criteria described by the national literature. A field survey was make in a company engaged in Fortaleza/CE at residential buildings in structural masonry, where from these data, a general analysis of errors which executives are more incidents on the rise masonry step is taken, it will also be held discussing the possible causes of such occurrences. As a result it was observed the most plumbs occurred in masonry, paging errors with the use of broken plates, failure to satisfy various joints with mortar and lack of standardization regarding the thicknesses of these joints. An important measure that can be taken to mitigate most of these errors is the use of appropriate and standardized tools and the use of skilled labor and prepared for this particular type of construction system.
\end{abstract}

Keywords: structural masonry, executives errors, pathological manifestations. 


\section{INTRODUÇÃO}

A indústria de construção civil no Brasil está numa fase bastante favorável e vem crescendo cada vez mais, juntamente com a inserção de novos sistemas construtivos, e é urgente que se usem tecnologias inovadoras e eficientes, proporcionando qualidade e ao mesmo tempo, menor custo que os sistemas construtivos convencionais atualmente aplicados no país. Segundo Pedroso (2004), destes sistemas, a alvenaria é um processo construtivo presente em todas as regiões, tendo seu uso como vedação ou como estrutura, a chamada alvenaria estrutural.

Segundo Kalil e Leggerini (2002), a alvenaria estrutural atingiu o auge no Brasil na década de 80, onde era utilizada principalmente para a construção dos conjuntos habitacionais, pois tinha um grande potencial de redução de custos, o que levou também a diversas construtoras e produtoras de blocos investirem nessa tecnologia para torná-las mais vantajosa. Porém, há alguns anos foram observados muitos problemas na sua execução, que acabaram tendo que ser reparados nessas obras. Esses problemas devemse ao uso de mão-de-obra não especializada ou sem conhecimentos necessários, materiais sem qualidade ou usados erroneamente (PRUDÊNCIO, 2003).

Esses últimos autores ainda citam que a inexperiência por parte dos profissionais com a utilização da alvenaria estrutural dificultou sua aplicação, causando várias manifestações patológicas nesse tipo de edificação, fazendo com que esse processo construtivo desacelerasse novamente.

Levando em conta que a alvenaria estrutural tem o papel não só de vedação, como também de sustentação estrutural, pequenas falhas cometidas na execução da obra podem acarretar em sérias manifestações patológicas não só relacionadas ao uso e ao custo, mas também à segurança, que poderá estar comprometida. Observa-se que uma série de erros que geralmente são cometidos na execução da alvenaria de vedação, dentre eles: a falta de prumo, dimensões inadequadas de juntas verticais e horizontais, modulação diferente da que é exigida em projeto, dentre outros, que se não forem sanados ainda durante a fase de elevação desta, certamente causarão alguma manifestação patológica podendo trazer junto prejuízos, incômodo aos usuários, dentre outros problemas. Diante do grande volume de obras em alvenaria estrutural que estão surgindo em âmbito nacional, torna-se interessante a caracterização desses erros.

Portanto, o objetivo deste trabalho é apontar os principais erros usualmente encontrados na fase de execução da alvenaria estrutural de blocos cerâmicos a partir de um levantamento de campo (estudo de caso), comparando-os com os critérios de aceitabilidade descritos pelas normas nacionais. Não será objeto deste artigo as repercussões ou consequências dos erros encontrados no levantamento de campo para com os usuários ou órgãos financiadores do empreendimento.

\section{METODOLOGIA}

Foi realizado um levantamento de campo em uma obra de prédios residenciais em alvenaria estrutural e que fazem parte do Programa Minha Casa Minha Vida, buscandose quais erros executivos eram mais incidentes na etapa de elevação das alvenarias e suas possíveis causas. A obra escolhida para ser feito o levantamento possui 4 torres, cada torre com 5 pavimentos e cada pavimento com 8 apartamentos, totalizando um total de 160 apartamentos. Existem quatro tipologias de apartamentos no empreendimento, que se diferenciam pelo tamanho, número de quartos e suítes de cada unidade, dependendo da torre onde elas se encontram. No período de tempo da realização deste trabalho a obra encontrava-se na etapa de término da alvenaria dos 
últimos pavimentos e início dos acabamentos nos primeiros pavimentos. Levando em conta a fase que a obra estava, foram tirados como amostragem apenas os apartamentos dos dois últimos pavimentos de cada torre, totalizando 64 apartamentos, o que significam $40 \%$ do número de total de unidades do empreendimento.

Foram escolhidos 7 itens para avaliação da alvenaria nas visitas aos apartamentos: Locação das paredes, onde foram analisadas se os eixos das paredes estão locados nos lugares indicados em projeto; Paginação dos blocos, onde foram analisados se os diferentes tipos de blocos estão alocados na parede da maneira indicada nos projetos de elevação; Prumo, onde foram medidas quais paredes estão com desaprumos, e o quanto elas estão (o valor representativo por apartamento foi tirado como o maior desaprumo encontrado nas paredes que o compõe); Alinhamento das paredes, onde foram analisadas as planicidades das paredes; Preenchimento das juntas, onde foram computadas as juntas secas que forem encontradas; Juntas Verticais, onde foram analisados os tamanhos ou a ausência das mesmas (o valor usado para representar aquele apartamento foi a máxima dimensão das juntas verticais que foram medidas); e Juntas Horizontais, onde também foram analisados os tamanhos ou a ausência das mesmas (o valor usado para representar aquele apartamento foi a máxima dimensão das juntas que foram medidas). Foram avaliadas todas as paredes dos apartamentos vistoriados.

Foi elaborada uma ficha de verificação para ser usada na fase de levantamento de dados na obra, que contém os serviços que serão avaliados, e quais os valores de aceitabilidade. De posse dos dados coletados foi feita uma análise geral de quais erros executivos são mais incidentes na etapa de elevação das alvenarias e suas possíveis causas. Buscou-se ainda apresentar as prováveis perdas geradas por esses erros, tais como a minoração da resistência estrutural do edifício, majoração dos custos que vão ser aumentados por conta de possíveis re-serviços e adequações de serviços sucessores ao da alvenaria, geração de maior volume de resíduos de construção civil e possíveis problemas de utilização do apartamento pelo morador.

\section{RESULTADOS}

Os dados levantados na obra estão dispostos nos quadros 1 a 4 para as torres 1 a 4 , respectivamente.

\section{Quadro 1 - Dados levantados na Torre 1}

\begin{tabular}{|c|c|c|c|c|c|c|c|c|c|c|c|c|c|c|c|c|}
\hline \multicolumn{17}{|c|}{ Torre 01} \\
\hline \multirow{2}{*}{ Itens Analisados } & \multicolumn{16}{|c|}{ APARTAMENTOS } \\
\hline & 401 & 402 & 403 & 404 & 405 & 406 & 407 & 408 & 501 & 502 & 503 & 504 & 505 & 506 & 507 & 508 \\
\hline $\begin{array}{l}\text { Valor máximo do desvio na } \\
\text { locação das paredes (mm) }\end{array}$ & 5 & 4 & 4 & 6 & 5 & 5 & 5 & 3 & 6 & 7 & 5 & 4 & 6 & 8 & 5 & 6 \\
\hline $\begin{array}{l}\text { Espessura máxima da junta } \\
\text { vertical }(\mathrm{mm})\end{array}$ & 60 & 60 & 35 & 20 & 50 & 25 & 70 & 15 & 17 & 22 & 24 & 20 & 16 & 70 & 14 & 20 \\
\hline $\begin{array}{l}\text { Espessura mínima da junta } \\
\text { vertical }(\mathrm{mm})\end{array}$ & 0 & 0 & 0 & 0 & 0 & 0 & 0 & 0 & 0 & 0 & 0 & 0 & 0 & 0 & 0 & 0 \\
\hline $\begin{array}{l}\text { Espessura máxima da junta } \\
\text { horizontal }(\mathrm{mm})\end{array}$ & 15 & 14 & 14 & 16 & 20 & 22 & 13 & 16 & 22 & 21 & 25 & 22 & 14 & 15 & 30 & 25 \\
\hline $\begin{array}{l}\text { Espessura mínima da junta } \\
\text { horizontal (mm) }\end{array}$ & 5 & 4 & 6 & 6 & 5 & 5 & 0 & 3 & 8 & 7 & 6 & 5 & 0 & 4 & 5 & 0 \\
\hline Diferença de prumo $(\mathrm{mm})$ & 11 & 4 & 3 & 16 & 4 & 5 & 3 & 12 & 8 & 6 & 4 & 2 & 10 & 1 & 6 & 10 \\
\hline $\begin{array}{l}\text { Modulação do blocos } \\
\text { conforme projeto? }\end{array}$ & $\mathrm{S}$ & $\mathrm{S}$ & $\mathrm{N}$ & $\mathrm{S}$ & $\mathrm{N}$ & $\mathrm{N}$ & $\mathrm{S}$ & S & $\mathrm{S}$ & $\mathrm{N}$ & $\mathrm{S}$ & $\mathrm{N}$ & $\mathrm{N}$ & $\mathrm{N}$ & $\mathrm{S}$ & $\mathrm{N}$ \\
\hline
\end{tabular}


Quadro 2 - Dados levantados na Torre 2

\begin{tabular}{|c|c|c|c|c|c|c|c|c|c|c|c|c|c|c|c|c|}
\hline \multirow{3}{*}{ Itens Analisados } & \multicolumn{15}{|c|}{ Torre 02} & \\
\hline & \multicolumn{16}{|c|}{ APARTAMENTOS } \\
\hline & 401 & 402 & 403 & 404 & 405 & 406 & 407 & 408 & 501 & 502 & 503 & 504 & 505 & 506 & 507 & 508 \\
\hline $\begin{array}{l}\text { Valor máximo do desvio na } \\
\text { locação das paredes (mm) }\end{array}$ & 5 & 7 & 7 & 8 & 3 & 7 & 6 & 5 & 4 & 7 & 4 & 7 & 5 & 6 & 2 & 7 \\
\hline $\begin{array}{l}\text { Espessura máxima da junta } \\
\text { vertical }(\mathrm{mm})\end{array}$ & 25 & 24 & 33 & 37 & 26 & 20 & 22 & 21 & 16 & 50 & 11 & 50 & 20 & 12 & 50 & 50 \\
\hline $\begin{array}{l}\text { Espessura mínima da junta } \\
\text { vertical }(\mathrm{mm})\end{array}$ & 0 & 0 & 0 & 0 & 0 & 0 & 0 & 0 & 0 & 0 & 0 & 0 & 0 & 0 & 0 & 0 \\
\hline $\begin{array}{l}\text { Espessura máxima da junta } \\
\text { horizontal }(\mathrm{mm})\end{array}$ & 24 & 31 & 14 & 15 & 21 & 24 & 22 & 21 & 15 & 13 & 20 & 22 & 13 & 15 & 16 & 18 \\
\hline $\begin{array}{l}\text { Espessura mínima da junta } \\
\text { horizontal (mm) }\end{array}$ & 0 & 4 & 0 & 0 & 0 & 6 & 7 & 8 & 4 & 3 & 0 & 5 & 6 & 5 & 4 & 7 \\
\hline Diferença de prumo (mm) & 10 & 15 & 12 & 16 & 7 & 6 & 9 & 12 & 8 & 8 & 10 & 6 & 5 & 12 & 4 & 10 \\
\hline $\begin{array}{l}\text { Modulação do blocos } \\
\text { conforme projeto? }\end{array}$ & $\mathrm{N}$ & $\mathrm{N}$ & $\mathrm{N}$ & $\mathrm{N}$ & $\mathrm{s}$ & $\mathrm{N}$ & $\mathrm{N}$ & $\mathrm{N}$ & $\mathrm{S}$ & $\mathrm{s}$ & $\mathrm{N}$ & $\mathrm{N}$ & $\mathrm{s}$ & $\mathrm{s}$ & $\mathrm{s}$ & $\mathrm{s}$ \\
\hline
\end{tabular}

Quadro 3 - Dados levantados na Torre 3

\begin{tabular}{|c|c|c|c|c|c|c|c|c|c|c|c|c|c|c|c|c|}
\hline \multicolumn{17}{|c|}{ Torre $\mathbf{0 3}$} \\
\hline \multirow{2}{*}{ Itens Analisados } & \multicolumn{16}{|c|}{ APARTAMENTOS } \\
\hline & 401 & 402 & 403 & 404 & 405 & 406 & 407 & 408 & 501 & 502 & 503 & 504 & 505 & 506 & 507 & 508 \\
\hline $\begin{array}{l}\text { Valor máximo do desvio na } \\
\text { locacão das paredes }(\mathrm{mm})\end{array}$ & 4 & 5 & 6 & 7 & 4 & 6 & 5 & 4 & 5 & 7 & 4 & 5 & 6 & 7 & 3 & 6 \\
\hline $\begin{array}{l}\text { Espessura máxima da junta } \\
\text { vertical }(\mathrm{mm})\end{array}$ & 43 & 32 & 60 & 50 & 46 & 20 & 50 & 15 & 20 & 23 & 37 & 18 & 27 & 35 & 34 & 50 \\
\hline $\begin{array}{l}\text { Espessura mínima da junta } \\
\text { vertical }(\mathrm{mm})\end{array}$ & 0 & 0 & 0 & 0 & 0 & 0 & 0 & 0 & 0 & 0 & 0 & 0 & 0 & 0 & 0 & 0 \\
\hline $\begin{array}{l}\text { Espessura máxima da junta } \\
\text { horizontal }(\mathrm{mm})\end{array}$ & 19 & 23 & 14 & 16 & 20 & 23 & 17 & 19 & 18 & 17 & 22 & 22 & 13 & 15 & 23 & 22 \\
\hline $\begin{array}{l}\text { Espessura mínima da junta } \\
\text { horizontal (mm) }\end{array}$ & 3 & 4 & 3 & 0 & 3 & 0 & 4 & 6 & 6 & 5 & 3 & 5 & 3 & 4 & 5 & 0 \\
\hline Diferença de prumo (mm) & 10 & 9 & 10 & 15 & 5 & 5 & 14 & 12 & 8 & 7 & 7 & 12 & 7 & 6 & 5 & 13 \\
\hline $\begin{array}{l}\text { Modulação do blocos } \\
\text { conforme projeto? }\end{array}$ & S & $\mathrm{N}$ & $\mathrm{N}$ & $\mathrm{S}$ & S & $\mathrm{S}$ & S & $\mathrm{N}$ & S & $\mathrm{N}$ & S & $\mathrm{N}$ & $\mathrm{N}$ & $\mathrm{S}$ & $\mathrm{S}$ & $\mathrm{N}$ \\
\hline
\end{tabular}

Quadro 4 - Dados levantados na Torre 4

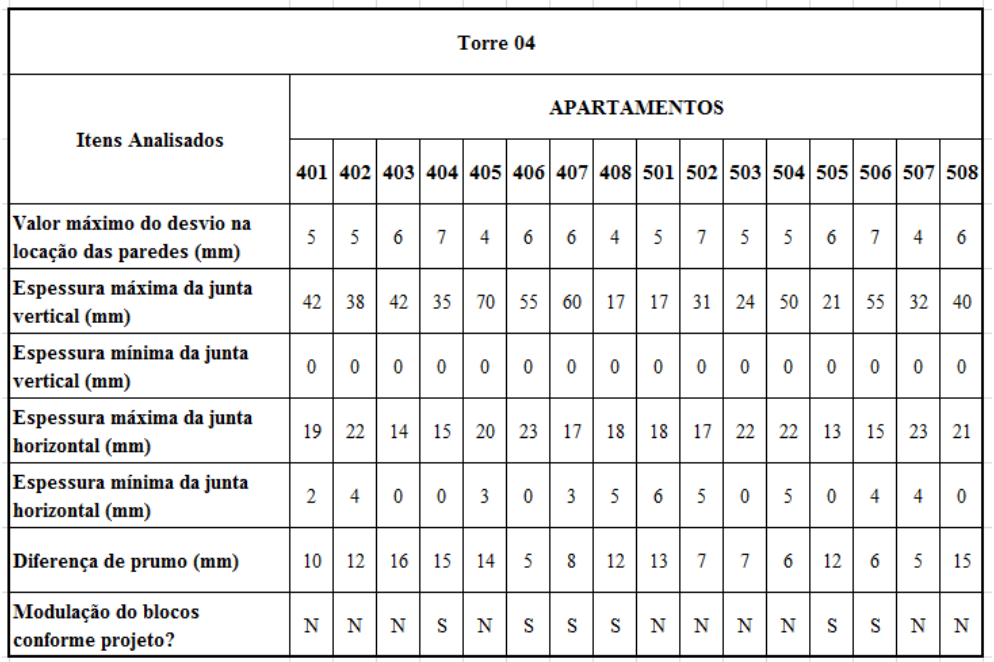

Será apresentado a seguir especificamente cada um dos itens que foram analisados nos apartamentos do estudo de caso. 


\subsection{Locação das paredes}

Foram conferidos se os eixos das paredes estavam locados nos lugares indicados em projeto, medindo-se os desvios, ou seja, a diferença de distância onde a parede era para estar locada, de acordo com o projeto, e onde ela realmente está. Na Figura 1 pode-se observar a média dos desvios máximos por torre e também os valores máximos de desvio na torre.

Figura 1 - Desvios médios e máximos de locação das paredes.

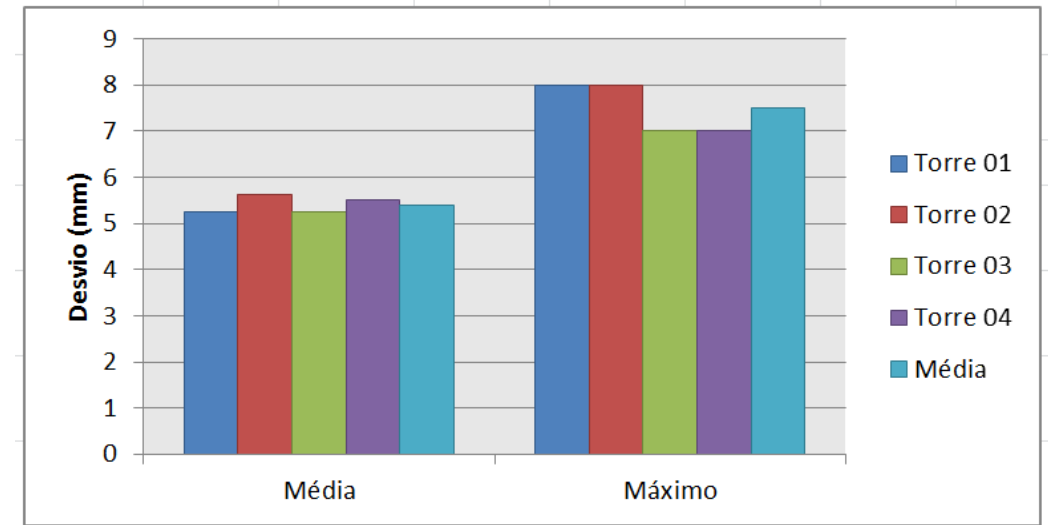

Apesar de todas as paredes apresentarem um pequeno desvio, observa-se que o mesmo não é representativo, pois os limites máximos admissíveis tirados da literatura é igual a 10 milímetros (Tomaz e Helene, 2000), enquanto as médias dos desvios medidos em campo variam entre 5 a 6 milímetros e valores máximos iguais a 8 milímetros. Considerou-se então que nenhuma das paredes da amostragem está fora do critério de aceitabilidade proposto.

\subsection{Modulação dos blocos}

Um item que se mostrou bastante falho na obra foi a modulação dos blocos. Os projetos de paginação da alvenaria elaborados pelo projetista praticamente não foram seguidos. Assim, no levantamento em obra verificou-se que 50\%, 44\%, 56\% e 37\% das alvenarias dos apartamentos das torres 1, 2, 3 e 4, respectivamente, apresentaram anomalias na modulação.

Com a modulação feita correta, a amarração das paredes seria simplificada, havendo um ganho significativo em termos da racionalização do sistema construtivo. Entretanto, sendo esta condição não atendida, foi necessária a utilização de unidades especiais para a correta amarração das paredes, o que pode trazer algumas consequências desagradáveis para o arranjo estrutural. Outra consequência da não realização da modulação correta da paginação está relacionada com a utilização de blocos quebrados para o ajuste da alvenaria. Esse procedimento incorreto resulta em um custo maior e uma racionalidade menor para a obra, que se verifica não só em relação à mão-de-obra para execução dos enchimentos propriamente ditos, mas também pelo seu efeito negativo no próprio dimensionamento da estrutura como um todo.

Verificou-se que em todas as torres, houve um número considerável de paredes que não seguiam critério nenhum de paginação, e que ainda contavam com muitos blocos quebrados para ajuste em espaços não modulados. Erros como esse ocorrem pela falta de mão-de-obra qualificada para a execução da alvenaria estrutural. Constatou-se ainda que muitos dos pedreiros que executaram a alvenaria eram acostumados somente com a execução da alvenaria de vedação e que não tinham experiência com a alvenaria 
estrutural. Um fator que também dificulta bastante a execução da paginação correta é a grande variabilidade no tamanho dos blocos cerâmicos, onde foram constatados lotes inteiros de com a largura de quase um centímetro a mais do que o padrão. A Figura 2 mostra o registro fotográfico feito em uma parede de um apartamento da torre 02, que ilustra a utilização de vários blocos que foram quebrados para completar a alvenaria, sem seguir a paginação correta da parede.

Figura 2 - Inadequação na modulação da alvenaria de um apartamento da torre 2

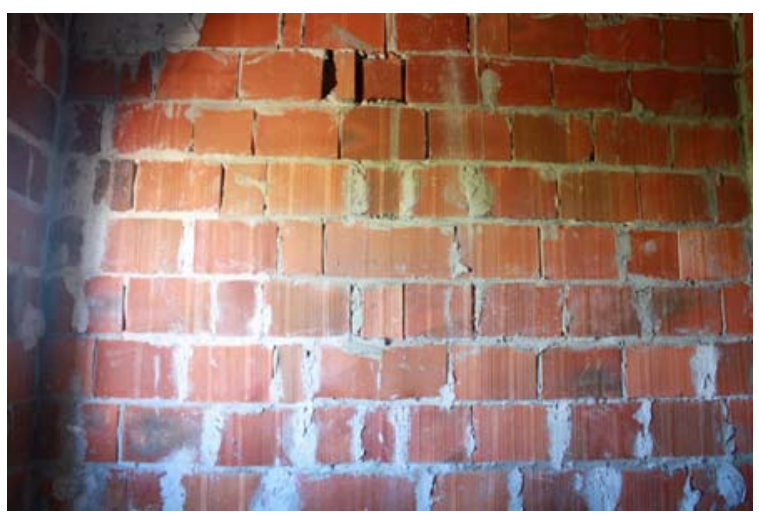

\subsection{Prumo e alinhamento das paredes}

A Figura 3 apresenta a média dos desaprumos máximos por torre e também os valores máximos na torre.

Figura 3 - Desaprumos médios e máximos das paredes levantados em campo

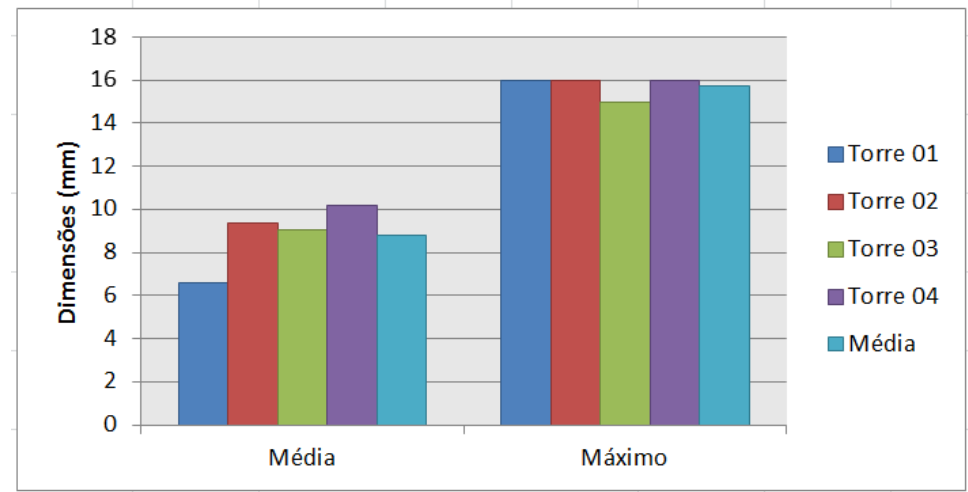

$\mathrm{Na}$ análise dos prumos e alinhamento das alvenarias, também se constatou uma quantidade considerável de apartamentos com pontos de desaprumo. Como mostrado na literatura, os limites admissíveis são de 2 milímetros para cada metro de alvenaria, então considerando-se uma alvenaria padrão do apartamento com 2,80 metros de altura, o limite admissível passa a ser 5,60 milímetros. Observando os dados levantados, percebe-se valores consideráveis, com as médias por bloco variando entre 8 e 10 milímetros. Observou-se ainda valores máximos de até 16 milímetros de desaprumo.

Uma das possíveis causas desses desaprumos está relacionada à falta de ferramentas adequadas para a execução do trabalho como os escantilhões e o nível de bolha. Um fator que também deve ser considerado é a exigência pela velocidade de execução do serviço, onde se percebeu ser constante no canteiro de obras. Essa exigência aumenta as chances de aparecerem mais erros, principalmente no que se refere nos quesitos que dependem da fase de elevação da alvenaria, que a etapa que mais demanda tempo. 
Além de causarem esforços adicionais na alvenaria que não foram considerados pelo projetista, os desaprumos e desalinhamentos existentes na alvenaria acarretarão em desperdícios futuros, isso por que na etapa de revestimento a espessura deste precisará ser maior para garantir a "planicidade" da parede. Esse aumento na espessura acarretará não só em um consumo maior de material, mas também demandará um maior tempo de mão-de-obra trabalhada para a execução do serviço.

Verificou-se, em campo, que a execução do serviço estava sendo feita sem a utilização de quase nenhuma das ferramentas que são recomendadas pela literatura e que foram comentadas nesse artigo. Da mesma forma da paginação, a grande variabilidade nas dimensões dos blocos cerâmicos facilita as falhas na execução da alvenaria estrutural quanto ao prumo e alinhamento das paredes.

\subsection{Juntas}

Na análise de preenchimento das juntas, foi conferida a existência, ou não, da argamassa que une os blocos, tanto as juntas horizontais como as verticais. Na Figura 4 pode-se observar uma parede com ausência de argamassa nas juntas verticais em alvenaria encontradas na torre 03. Em todos os apartamentos visitados, foi encontrada pelo menos uma parede com juntas sem o preenchimento. Em alguns casos os blocos cerâmicos estavam juntos um do outro sem nenhum espaçamento entre eles, porém em alguns apartamentos (como foi mostrado na Figura 4) foi deixado o espaçamento da junta, mas o mesmo não foi preenchido com a argamassa.

Segundo Romah (sem data), o não preenchimento dessas juntas verticais causa uma redução na resistência das estruturas aos esforços laterais e principalmente uma menor rigidez à flexão e ao cisalhamento. As faltas das juntas ainda causarão também a facilidade da entrada de intempéries, o que causará outras manifestações patológicas que acarretará consequências diretas aos usuários finais.

Figura 4 - Alvenaria com juntas verticais sem preenchimento

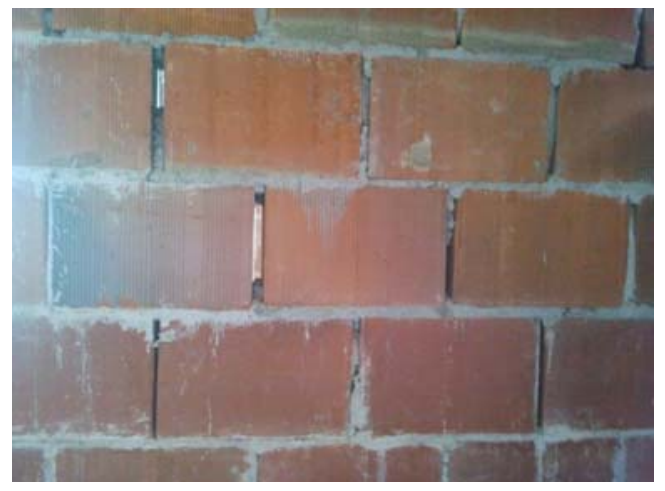

Fez-se uma análise também as juntas verticais e horizontais. Pôde-se observar que os apartamentos apresentaram algumas juntas verticais com espessura média de 35 milímetros e dois valores pontuais de 70 milímetros, sendo estes valores elevados se comparados com os limites encontrados na literatura que recomendam juntas médias de 10 milímetros. As Figuras 5-a e 5-b apresentam as aberturas médias e máximas de juntas verticais e horizontais, respectivamente, dos apartamentos das torres inspecionadas observadas nas alvenarias dos apartamentos avaliados. 
Figura 5 - a) Juntas verticais médias e máximas levantadas em campo; b) Juntas horizontais médias e máximas levantadas em campo;
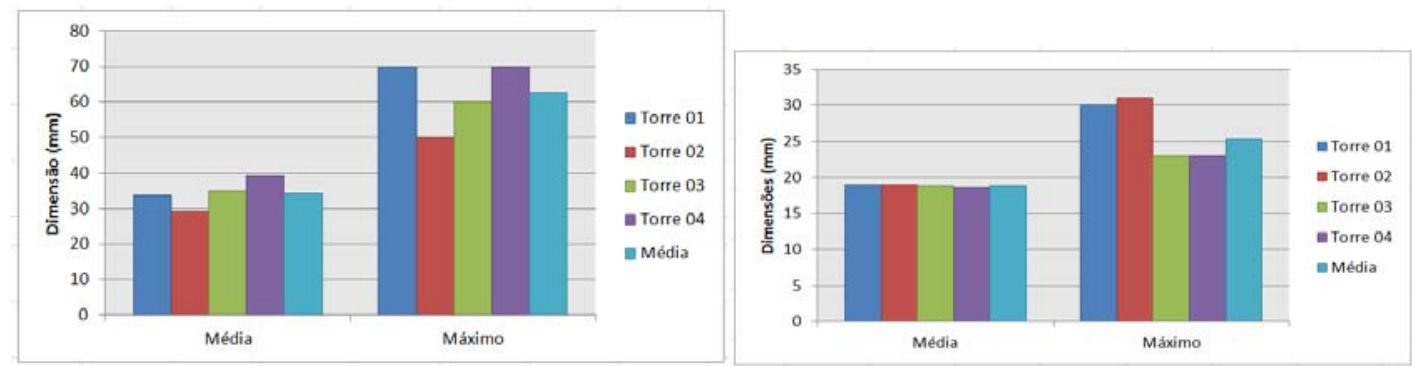

Observa-se que os apartamentos também apresentam algumas juntas horizontais elevadas (com a média em torno de 20 milímetros), se comparadas com os limites encontrados na literatura que recomendam juntas médias de 10 milímetros. Foram verificados alguns pontos em que nota-se a ausência da junta horizontal, o que é muito prejudicial à alvenaria.

As juntas horizontais se mostraram menos espessas que as verticais, mesmo assim ainda apresentam inconformidades se comparadas às indicações das normas, que ainda afirmam que juntas espessas diminuem gradativamente a resistência à compressão da alvenaria

\subsection{Outros erros}

Além dos erros executivos apresentados nos itens acima, também foram feitos registros de outros erros e manifestações patológicas que foram encontrados pontualmente durante a inspeção dos apartamentos, dentre eles: grauteamento mal executado deixando vazios (Figura 6-a), juntas fissuradas (Figura 6-b), rasgo na alvenaria decorrente da tubulação elétrica executada após a alvenaria e umidade nos blocos (Figura 6-c) e; fungos e bolor nos blocos (Figura 6-d).

Figura 6 - a) Grauteamento mal executado; b) Fissura na alvenaria;

c) Rasgos na alvenaria; d) Bolor em blocos

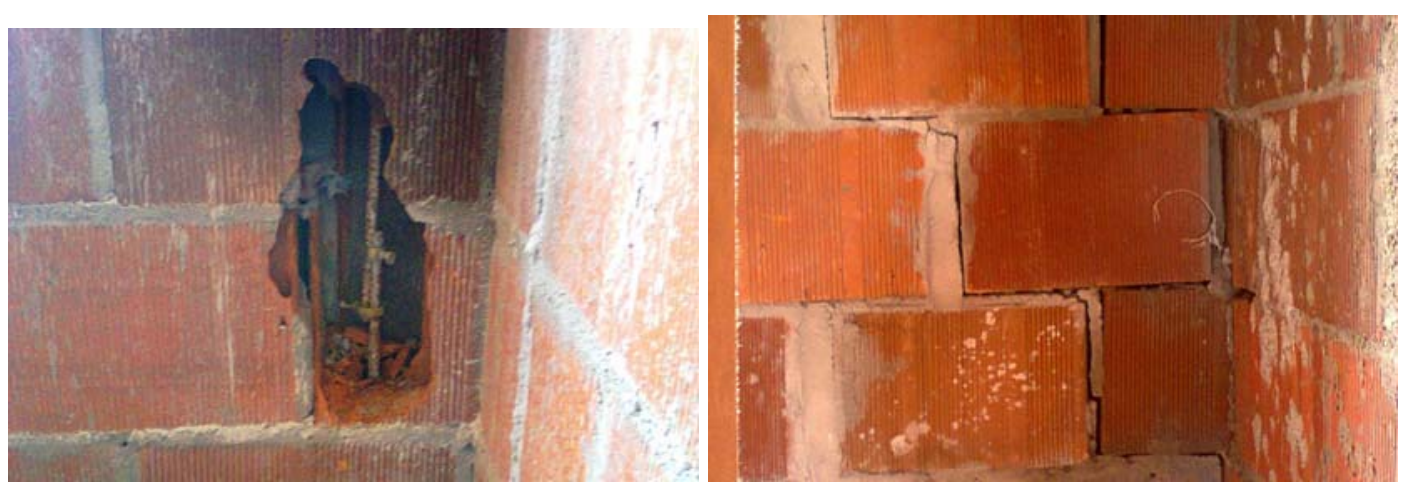



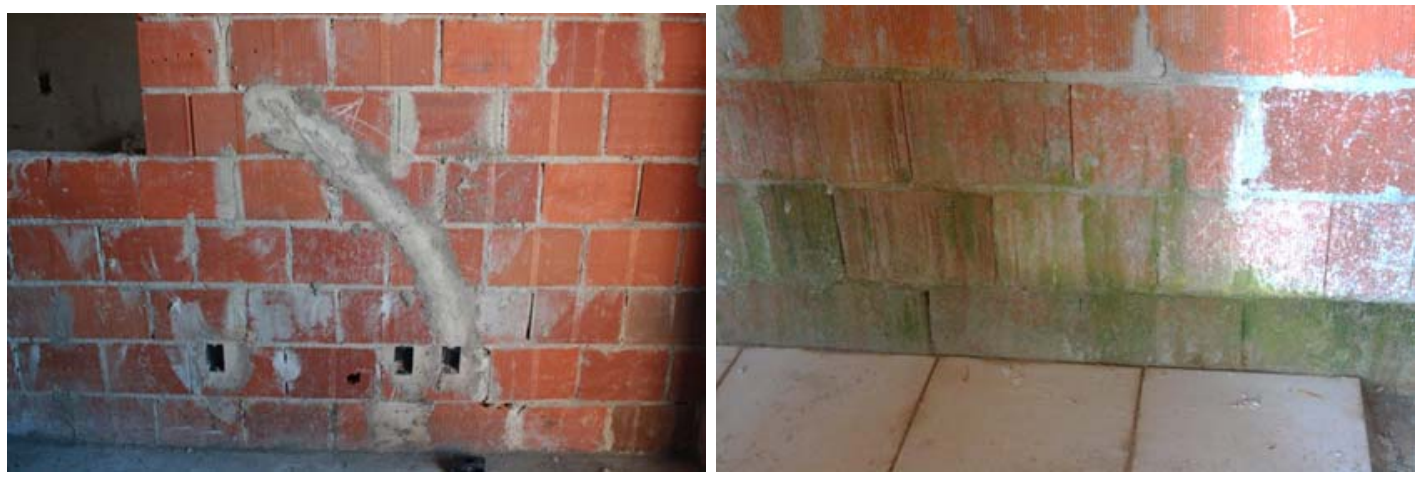

\section{CONCLUSÕES}

Diante dos dados levantados, podem-se tirar as seguintes conclusões com base nos resultados apresentados:

1) Na item locação das paredes, apesar de a maioria destas apresentarem algum desvio, observou-se que o mesmo está dentro dos critérios de aceitabilidade, pois os valores máximos admissíveis para esses desvios são de 10 milímetros, enquanto a média de desvios das alvenarias foi de 5,5 milímetros.

2) Sobre a paginação da alvenaria, notou-se que não é dada muita importância para este item na obra. Em aproximadamente 50\% da amostra foram encontradas paredes que apresentavam diferenças entre o projeto de paginação e o que foi executado.

3) Na conferência dos prumos das paredes, observa-se que o desaprumo também é um erro bastante comum. A média dos desaprumos medidos nos apartamentos foi 9 milímetros, enquanto o nível de aceitabilidade para as alvenarias avaliadas é de 5,6 milímetros.

4) As juntas de argamassas da alvenaria foi um dos pontos mais críticos dos erros levantados pois foram constatadas muitas juntas sem preenchimentos, principalmente as verticais. Notou-se grande variabilidade da espessura das juntas horizontais, com espessuras médias máximas de 18 milímetros e médias mínimas de 3,5 milímetros, enquanto os critérios de aceitabilidade são de 10 milímetros, podendo variar apenas 3 milímetros, para mais ou para menos. Com relação às juntas verticais, observou-se juntas com espessuras de 70 milímetros, enquanto que o valor limite é de 10 milímetros. Além de diminuir a resistência da alvenaria, juntas muito espessas afetam a paginação da alvenaria.

5) Outros erros e manifestações patológicas foram encontrados durante o levantamento de campo, como pontos inadequados de grauteamento, junta de argamassas com fissuras, rasgos na alvenaria para execução de pontos elétricos e umidade excessiva na base das paredes. Todos esses erros causam problemas tanto para a segurança estrutural da edificação, como no surgimento de manifestações patológicas que afetarão diretamente o usuário.

Muitos desses erros encontrados poderiam ser evitados, ou pelo menos amenizados com a utilização de todas as ferramentas disponíveis para a execução da alvenaria estrutural, bem como com a utilização de mão-de-obra experiente e capacitada. Outro fator que também merece importância é o controle de tamanho dos blocos, onde não devem ser utilizados blocos com dimensões fora de padrão. 


\section{REFERÊNCIAS}

ASSOCIAÇÃO BRASILEIRA DE NORMAS TÉCNICAS. NBR 15812: Alvenaria estrutural Blocos cerâmicos Parte 2: Execução e controle de obras. Rio de Janeiro, 2010.

CAMACHO J. S. Projeto de edifício de alvenaria estrutural. Universidade Estadual Paulista, Ilha solteira, São Paulo, 2006.

FREITAS JR, J. A.; Construção Civil II: Alvenaria Estrutural. Universidade Federal do Paraná, Curitiba, Sem data.

KALIL, S. B.; LEGGERINI, M. R.; Alvenaria Estrutural. Curso de Graduação. Pontifícia Universidade Católica do Rio Grande do Sul. Porto Alegre, 2002.

MANZIONE, L.; Projeto e execução de Alvenaria estrutural - Primeiros passos da qualidade no canteiro de obras. São Paulo, 2004.

PEDROSO, G. M.; O Desenvolvimento do sistema construtivo em alvenaria estrutural no estado do Tocantins - IV Jornada de iniciação cientifica do CEULP/ULBRA, 2004.

PRUDÊNCIO JR., L. R; OLIVEIRA, A L.; BEDIN, C.A. Alvenaria Estrutural de Blocos de Concreto. Associação Brasileira de Cimento Portland, Gtec - Florianópolis, 2002.

RAMALHO, M.A.; CORRÊA, M.R.S. Projeto de edifícios de alvenaria estrutural. São Paulo: Pini, 2003.

RICHTER, C.; MASUERO, A.B.; FORMOSO, C.T.; Manifestações patológicas de alvenaria: uma análise de causa e efeito. In: CONGRESSO INTERNACIONAL SOBRE PATOLOGIAS E RECUPERAÇÃO DE ESTRUTURAS, 12., 2010, Córdoba.

ROMAN, H. R.; SIGNOR, R.; RAMOS, A. S.; Análise de Alvenaria Estrutural. Grupo de Desenvolvimento de Sistemas de Alvenaria - Santa Catarina, Sem Data.

THOMAZ, E.; HELENE, P., Boletim técnico: Qualidade no projeto e na execução de alvenaria estrutural e de alvenarias de vedação em edifícios. São Paulo: Escola Politécnica da USP, 2000. 